\title{
Breast Infection, CTCAE
}

National Cancer Institute

\section{Source}

National Cancer Institute. Breast Infection, CT CAE. NCI Thesaurus. Code C143336.

A disorder characterized by an infectious process involving the breast. 